\title{
Teacher professional development through a physical computing workshop
}

\author{
Tom Neutens \\ Electronics and Information Systems, \\ Ghent University
}

\author{
Francis wyffels \\ Electronics and Information Systems, \\ Ghent University
}

\begin{abstract}
In recent years there has been a push towards more CS and STEM education in Flanders. These two domains require a set of skills with which teachers are currently often unfamiliar. To enable teachers to acquire these skills, professional development programs should be implemented. In this paper we first present a way of identifying the properties of such a program to allow comparison with other programs. Next, we describe a professional development program in the form of a physical computing workshop.
\end{abstract}

\section{CCS Concepts}

- Computer and Information Science Education $\rightarrow$ Computer science education;

\section{Keywords}

computer science education, STEM education, teacher professional development

\section{INTRODUCTION}

In 2015 the Flemish minister of education presented the STEM framework for education in Flanders [2]. The framework provides general principles and goals for secondary schools, with the objective to encourage schools to introduce STEM into the curriculum. Similar frameworks exist in other countries like the UK [5] and the US [1].

The framework interprets STEM education as creating a cross discipline, inquiry- and project-based, collaborative learning environment. This environment should focus on problem solving and creativity, and aim to inspire and motivate children towards science in general. It also mentions programming and computational thinking in several places.

The framework provides ten dimensions along which teachers and educators have to work to successfully implement STEM in their school. However it does not define a focus on certain aspects of STEM, nor does it provide any practical guidelines about the implementation. Taking into

Permission to make digital or hard copies of part or all of this work for personal or classroom use is granted without fee provided that copies are not made or distributed for profit or commercial advantage and that copies bear this notice and the full citation on the first page. Copyrights for third-party components of this work must be honored. For all other uses, contact the owner/author(s).

WiPSCE '16 October 13-15, 2016, MÃijnster, Germany

(C) 2016 Copyright held by the owner/author(s).

ACM ISBN 978-1-4503-4223-0/16/10.

DOI: http://dx.doi.org/10.1145/2978249.2978270 account the rules of the Flemish education system, schools are free in how they implement STEM. However, the practical implementation of the framework can be a big challenge for several reasons: (1) In Flanders, there is no such thing as a STEM teacher; (2) There is a lot of available STEM course material but teachers are unable to find and/or select the right material; (3) Teachers tend to think within the borders of their discipline. Collaboration across different disciplines is often difficult; (4) Current evaluation techniques focus mainly on evaluating the product and not the STEM process; (5) Teachers are often uncomfortable with an open learning environment, they tend to fear losing control because their knowledge about different STEM subjects is not extensive enough. Consequently, research needs to be conducted to determine a set of best practices for STEM.

\section{PHYSICAL COMPUTING}

In this paper we analyze a teacher training program that prepares teachers to conduct an Artbots physical computing workshop with children ages 10 to 12 . In the Artbots workshop, children learn to build and program a robot that creates art. It focuses on creating an open, inquiry-based learning environment in which children are able to express their creativity. The aim is to introduce children to electronics and programming and motivate them to pursue a scientific career. The teacher training program, prepared teachers by letting them build their own artbot.

\subsection{Goal and structure}

The goal of the program was to teach teachers how to assist children, ages 10 to 12 , in designing and creating their own robot. The two-day teacher training program prepares teachers by letting them design and build their own artbot [6]. It consists of the following activities: (1) A general introduction session; (2) An individual brainstorm in which the participants think up a concept for their artbot; (3) A CSUnplugged activity, used to introduce the concept of CSUnplugged and emphasize the importance of relating the activity back to a computer science concept; (4) A short introduction to building and programming a robot based on the Dwenguino platform, an Arduino compatible microcontroller board; (5) Building their first riding robot in small groups. These groups are made by clustering people which had similar artbot concepts; (6) Building their own artbot based on the skills acquired during the program.

On the first day teachers went through all but the last of these activities. On the second day the program vision was reiterated and a new CSUnplugged activity was performed, 
afterwards participants had time to build their artbot.

\section{PROGRAM CLASSIFICATION}

To relate our training program to other programs described in literature, we believe a set of criteria should be derived to easily identify professional development programs. Currently, these programs are difficult to relate since there is no framework in which they can be fitted. With this classification we try to suggest a framework to identify professional development programs. The criteria used here are by no means complete, they should evolve into a more generally accepted framework agreed upon by all stakeholders. Our program was classified by scoring it on the criteria used by Mentz et al. [4]. These criteria are based on the professional development review, performed by Guskey [3].

On some of these criteria, the program performs very strongly: There was a large focus on enhancing teachers content knowledge by giving them an introduction to electronics and programming. Pedagogical knowledge didn't lag behind, participants were shown the value of inquiry-based learning, collaborative learning and teaching, different types of learning activities and the value of open assignments. Collaboration was promoted by requiring the participants to work together during the program, for example, when constructing their robot in groups of two. The program was conducted in the school and additional support was given during the project week the school had organized. During this week the secondary school teachers performed the Artbots project with possibly future students which were in the last year of primary school. On the other side of the spectrum, some characteristics such as: evaluation, building leadership and job embeddedness received little attention.

\section{PROGRAM EVALUATION}

\subsection{Teacher observations}

During the training program the teachers were observed to identify common problems and behaviours. Some of the more interesting observations where: (1) Teachers needed a lot of time to build their two-wheeled riding robot. This was mainly due to the lack of planning and their inability to predict certain problems. Some participants built a carriage with wheels and tried to add electrical components at the end, in most cases this led to an entire rebuild of the robot. Other groups, who did include the motors, often didn't attach them to the chassis of the carriage. As a result the robot didn't ride. (2) During programming teachers experienced multiple problems. Some teachers requested a written out documentation of what each of the blocks in the Ardublock could be used for. (3) In general, the participants had a noticeable fear of breaking something, either by incorrectly plugging something into the breadboard connected to the microcontroller or by writing a piece of code which, they thought, would destroy part of their robot.

\subsection{Teacher reactions}

To assess the program, the nine participants filled out a survey with 22 questions on a five-point Likert scale. The questions were split into three categories: ten questions about their technical knowledge, seven about their pedagogical knowledge and five about the teacher's self-efficacy. The questions where scored on agreement with the workshop philosopy $(1=$ not agree, $5=$ completely agree). The technical questions scored 3.93 on average, the pedagogical questions 3.11 and the self-efficaly questions 3.51 .

\section{RESULTS AND DISCUSSION}

It is difficult to draw any solid conclusions based on the collected data since the number of participants was limited and not statistically significant. However, based on the survey results and teacher observations we can make some interesting observations about the program.

Considering our results, participating teachers seem to believe their content knowledge has increased, however not to such an extent to make them confident enough to implement CS focused STEM activities themselves. It also seems that current pedagogical habits are difficult to change. An open, collaborative, inquiry-based teaching environment with focus on the learning process, which teachers believe has a lot of value, is a big step for them. This indicates that a two-day physical computing training program does not provide sufficient background to allow teachers to effectively implement a computing related STEM project in their classroom.

Although teacher confidence and technical knowledge was limited after the training program, the teachers did successfully assist children during the Artbots workshop week. This indicates that they gained sufficient confidence and content knowledge to guide children while building their artbot.

\section{CONCLUSION}

Professional development programs can take on many forms, this makes it difficult to select the right type of program in different situations. Identifying the characteristics of these programs is key in selecting the right program. Our results indicate that a two-day physical computing training program is not sufficient to give teachers enough confidence to implement CS focused STEM projects in their classroom. It does, nevertheless, provide a basic overview of certain CS and STEM concepts and teachers feel like they learn a lot from these training programs.

\section{REFERENCES}

[1] O. Astrachan, J. Cuny, C. Stephenson, and C. Wilson. The CS10K project: Mobilizing the community to transform high school computing. SIGCSE'11 Proceedings of the 42nd ACM Technical Symposium on Computer Science Education, pages 85-86, 2011.

[2] D. O. en Vorming. Stem-kader voor het vlaamse onderwijs, November 2015.

[3] T. R. Guskey. The characteristics of effective professional development: A synthesis of lists. 2003.

[4] E. Mentz, R. Bailey, B. Breed, and M. Havenga. Empowering information technology teachers through professional development: an evaluation. In Proceedings of the 8th Workshop in Primary and Secondary Computing Education, pages 37-38. ACM, 2013.

[5] H. Schweingruber, T. Keller, H. Quinn, et al. A Framework for K-12 Science Education:: Practices, Crosscutting Concepts, and Core Ideas. National Academies Press, 2012.

[6] F. wyffels, W. Van de Steene, J. Roets, M.-C. Ciocci, and J. P. Carbajal. Building ArtBots to Attract Students into STEM Learning. ArXiv e-prints, Aug. 2016 . 